\title{
Bernard-Soulier Syndrome
}

National Cancer Institute

\section{Source}

National Cancer Institute. Bernard-Soulier Syndrome. NCI Thesaurus. Code C84595.

A rare, autosomal recessive bleeding disorder characterized by deficiency or absence of the Ib/IX/V complex on the surface of platelets. It results in thrombocytopenia, prolonged bleeding time and the presence of giant platelets. 